\title{
O trabalho como princípio educativo no MST: um estudo de caso do Assentamento Padre Réus
}

Beliza Stasinski Lopes ${ }^{1}$, Cheron Zanini Moretti ${ }^{2}$

${ }^{1}$ Universidade de Santa Cruz do Sul - UNISC. Programa de Pós-Graduação em Educação. Avenida Independência, 2293. Universitário, Santa Cruz do Sul - RS. Brasil. beliza6@yahoo.com.br. ${ }^{2}$ Universidade de Santa Cruz do Sul - UNISC

RESUMO. A pesquisa realizada no Assentamento Padre Réus, no município de Encruzilhada do Sul, interior do Rio Grande do Sul, traz o problema do trabalho como princípio educativo, através da reconstituição da trajetória de 37 famílias assentadas no seu percurso da zona urbana de Sapiranga, onde trabalhavam na indústria calçadista, até o lote conquistado na reforma agrária através de seu processo de luta social. Nessa trajetória foi apresentado o "tempo de acampamento" como um momento de preparação para o trabalho, onde se valorizam o trabalho camponês, o cultivo da terra e a produção de alimentos. A metodologia da pesquisa partiu de seis entrevistas com os(as) trabalhadores(as) que narraram suas experiências individuais e coletivas. $\mathrm{O}$ texto foi construído através da análise de material coletado, com a técnica de análise de conteúdo. Pode-se concluir que "o trabalho" foi central na mobilização dessas famílias até o campo, e que "o trabalho" no lote tem sido um princípio educativo para essas famílias, particularmente, a partir das escolhas que fazem no processo de produção.

Palavras-chave: Trabalho, Educação, Trajetória, Campo e Produção. 


\title{
The work as educational principle in the MST: a case study Padre Réus Settlement
}

\begin{abstract}
The research carried out at the Padre Réus settlement in the municipality of Encruzilhada do Sul, in the Rio Grande do Sul, presents the problem of work as an educational principle, through the reconstitution of the trajectory of 37 families settled in their urban area of Sapiranga, where worked in the footwear industry, up to the land won in agrarian reform through its process of social struggle. In this trajectory, "camp time" was presented, as a moment of preparation for work, where peasant work, land cultivation and food production are valued. The methodology of the research was based on six interviews with the workers who narrated their individual and collective experiences; the text was constructed through the analysis of the collected material, with the technique of content analysis. It can be concluded that "work" was central to the mobilization of these families to the countryside, and that "work" in the lot has been an educational principle for these families, particularly from the choices they make in the production process.
\end{abstract}

Keywords: Work, Education, Trajectory, Countryside and Production. 


\title{
El trabajo como principio educativo en el MST: un estudio de caso del Asentamiento Padre Réus
}

\begin{abstract}
RESUMEN. La investigación realizada en el Asentamiento Padre Réus, en el municipio de Encruzilhada do Sul, interior de Rio Grande do Sul, trae el problema del trabajo como principio educativo, a través de la reconstitución de la trayectoria de 37 familias asentadas en su recorrido de la zona urbana de Sapiranga, donde Trabajaban en la industria del calzado, hasta el lote conquistado en la reforma agraria a través de su proceso de lucha social. En esa trayectoria se presentó el "tiempo de campamento" como un momento de preparación para el trabajo, donde se valora el trabajo campesino, el cultivo de la tierra y la producción de alimentos. La metodología de la investigación partió de seis entrevistas con los trabajadores que narraron sus experiencias individuales y colectivas, el texto fue construido a través del análisis del material recolectado, con la técnica de análisis de contenido. Se puede concluir que "el trabajo" fue central en la movilización de esas familias hasta el campo, y que "el trabajo" en el lote ha sido un principio educativo para esas familias, particularmente, a partir de las elecciones que hacen en el proceso de producción.
\end{abstract}

Palabras clave: Trabajo, Educación, Trayectoria, Campo y Producción. 


\section{Introdução}

Este artigo trata do tema da educação informal ${ }^{\mathrm{i}}$ no Movimento dos Trabalhadores Rurais Sem Terra (MST), a partir de um estudo de caso da trajetória dos/das assentados/as no Assentamento Padre Réus, no município de Encruzilhada do Sul, no Rio Grande do Sul, que busca compreender, através de suas narrativas, a experiência que tiveram, no "tempo do acampamento" e no assentamento, bem como as vivências que permitiram a esse conjunto de trabalhadores voltar ao campo.

É importante salientar que a educação é compreendida, neste trabalho, como a vivência que esses trabalhadores tiveram no interior do movimento social. No seu processo de aprendizado de viver no campo, houve um período de transição, que passou, necessariamente pela organização nas fileiras do MST. Nesse sentido, é importante escutar as falas, que rememoram tal experiência.

Quer-se saber se o trabalho, nessa trajetória, figura como um princípio educativo, o qual, no caso do MST, permite aos/às trabalhadores(as) saírem de zonas urbanas e voltarem ao campo, lugar em que muitos nasceram.

Apoiado na ideia de Ribeiro (2009, p. 49) entende-se que:
1) O trabalho se institui como princípio educativo, considerando a educação em sua dupla dimensão de adaptação e de emancipação - por ser práxis que comporta, como um de seus fundamentos integração entre ciência, cultura e trabalho. 2) $\mathrm{O}$ trabalho, social do capitalismo, ao se instituir como trabalho alienado, reforça o sentido de adaptação e impõe limites à dimensão emancipatória da educação (2009, p. 49).

A descoberta do caminho que esses trabalhadores/as percorreram permite auferir alguns aprendizados, sendo na constituição de grupos no interior do acampamento, seja no assentamento, no momento de pensar um trabalho de cultivo combinado ou coletivo. $\mathrm{O}$ ambiente de solidariedade que o movimento social propicia é considerado um fator preponderante que constitui a prática social dos/das trabalhadores/as.

O objetivo é aprender quais são as novas práticas sociais, baseadas em um processo de educação que se gesta no interior do movimento, que possibilitam pensar uma pedagogia da luta do movimento social.

Para isso, foi realizada uma descrição baseada em entrevistas que abordaram a condição social das famílias do assentamento Padre Réus antes, durante, e depois de assentadas. 


\section{Metodologia}

Este trabalho foi realizado por meio de seis entrevistas, na tentativa de buscar memórias, através das narrativas que esses/as trabalhadores/as assentados/as fazem da sua prática política e social, remetendo a sua trajetória. A partir das suas falas e da apreensão de suas experiências, constrói-se a narrativa do trabalho.

$\mathrm{Na}$ elaboração dos dados, foram aplicadas seis entrevistas semiestruturadas entre os assentados. Os nomes estipulados são fictícios e a escolha dos/das entrevistados/as ocorreu através de uma cadeia de informações, a qual começou com o coordenador do Assentamento, Mário, que indicou o diálogo com os demais assentados, o que contribuiu para a escolha dos demais entrevistados/as. No total das seis entrevistas, tem-se o depoimento de três mulheres e três homens. Vera foi a segunda entrevistada. Ela é uma mulher de 33 anos, possui cinco filhos e mora com a família no assentamento. A terceira entrevistada se chama Júlia, tem 28 anos, dois filhos e não conhecia o trabalho no campo antes de obter o lote. $\mathrm{O}$ quarto entrevistado se chama João, pertenceu à frente de massas quando esteve acampado, trabalhou cerca de quatro anos aproximando novos integrantes para o MST. Também se entrevistou o Paulo, um senhor de 65 anos e Alcina, de aproximadamente 59 anos.

Os dados coletados foram organizados para uma melhor apreensão tanto dos aspectos gerais, como a história das famílias e do assentamento rural, quanto dos individuais, como as suas percepções sobre as experiências vivenciadas no movimento da luta pela terra. A partir da análise do material, pretendeu-se aprofundar o conhecimento sobre o objeto de pesquisa.

Para realizar uma descrição da situação das famílias e sua condição socioeconômica, foi utilizado um relatório elaborado pela EMATER-RS, em que foi realizada a aplicação de questionário aos/às trabalhadores/as e sistematizados os dados que foram produzidos durante o ano de 2003.

Essa pesquisa está baseada em dois métodos desenvolvidos pela pesquisa social, a análise de conteúdo das entrevistas, que oferece qualidade aos trechos que dialogam com nosso problema, e o estudo de trajetórias de vida, a partir de narrativas. As entrevistas foram realizadas ao longo de 2011.

O início da trajetória: a adesão ao MST 
Os/as trabalhadores/as já estavam no assentamento quando foram realizadas as entrevistas. Nesse sentido, foi realizado um trabalho de memória, para que eles pudessem reconstruir o passado, trazendo suas lembranças mais significativas em relação ao trabalho, verificando as escolhas tomadas em optar pela organização no movimento social e também a vivência no movimento, até chegarem à situação atual no assentamento. Eles/as falam de um tempo presente que lhes possibilita a comparação com a vida antes do movimento social e o aprendizado que obtiveram neste, porque, como relatam, a luta não foi em vão. $\mathrm{E}$, o futuro que projetavam com esperança se realizou, mas não sem luta social.

No começo foi difícil porque a gente era acostumada a ser assalariado por mês, cada empregado a cada quinzena ganhava o seu salário, depois, quando viemos para cá, levou em média, que eu me lembro, um ano e meio mais ou menos para sair o primeiro recurso. Claro que para a alimentação, né, sempre tinha alguma coisa, mas foi sofrido no começo, menina do céu, ainda mais nós que viemos do acampamento e não tinha nada. Era só um gibão para cozinhar debaixo de uma árvore e um barraco. Dalí começaram a vim um tempo para começar a fazer galpão (...). Eu só pensava na minha ideia de voltar embora, eu só queria voltar (Vera, 32 anos).

Segundo a EMATER (2003), as
Padre Réus, ao chegar ao município de Encruzilhada do Sul, no dia 15 de dezembro de mil novecentos e noventa e oito, receberam do Instituto de Colonização e Reforma Agrária (INCRA) uma propriedade denominada pelos assentados de "lote" com vinte e cinco hectares, para se estabelecerem na terra. A fazenda desapropriada com fins à Reforma Agrária tinha 1.214,5 hectares, na região denominada Foles, no município de Encruzilhada do Sul, próximo à divisa de Amaral Ferrador, no interior do Rio Grande do Sul.

As famílias contempladas com as terras são provenientes de no mínimo nove municípios do: Tenente Portela, Erexim, Redentora, Santo Ângelo, Três Passos, Erval Seco, Passo Fundo, Horizontina e Camaquã. A maioria delas residia no município de Sapiranga antes de aderirem ao MST e ingressarem na luta pela terra. Atuavam basicamente como trabalhadores/as do setor calçadista, mas também se constatou que, entre os homens, havia profissões no setor da construção civil e, entre as mulheres, de empregada doméstica. Também, em sua maioria, eram filhos e filhas de camponeses que abandonaram a terra natal para buscar oportunidades de emprego em regiões industrializadas. 
Estas famílias tiveram o primeiro contato com o MST através do diálogo com a equipe responsável por recrutar novos adeptos às fileiras do movimento com vistas à formação de novos acampamentos, e que formavam, portanto, a Frente de Massas.,. Alguns também conheceram a proposta através de parentes, como pais e tios, ou conhecidos, ou, no caso da maioria que veio de Sapiranga, da relação intermediada pelo Sindicato dos Sapateiros.

Foram acampar no início do ano de mil novecentos e noventa e oito, na formação de um acampamento que ocorreu no município de Piratini, e muitos participaram neste município de sua primeira ocupação de terras, uma ação direta para denunciar a existência de latifúndio. Permaneceram alguns meses em Piratini, depois saíram em marcha para Porto Alegre e montaram acampamento na cidade de Viamão. $\mathrm{O}$ acampamento era composto por algumas centenas de famílias, e sua organização interna era realizada através de núcleos compostos, cada um, por vinte e cinco famílias, as quais se reuniam através de proximidades - como região, parentesco e afinidades - e também de organização por setores educação, saúde e segurança.

As famílias do assentamento Padre Réus faziam parte de, pelo menos, dois núcleos, que foram sorteados pela coordenação do MST para ocupar as terras desapropriadas na Fazenda Santa Rita, em Encruzilhada do Sul, entre aqueles que estavam há mais de seis meses acampados, regra de tempo estabelecida pelo próprio movimento como critério para receber as terras. Até o dia quinze de dezembro de mil novecentos e noventa e oito, quando receberam as terras em Encruzilhada do Sul, já estavam acampados há pelo menos dez meses.

\section{A estrutura do acampamento: uma forma de educação política}

Em vinte e cinco anos de história do MST-RS (ou aproximadamente trinta anos se toma com marco histórico o Acampamento em Encruzilhada Natalino), pode-se dizer que o "acampamento" tem se constituído como uma das principais formas de resistência e mecanismo de luta pela Reforma Agrária no Brasil, desde o ângulo da organização popular.

O acampamento constitui-se como um espaço importante na mobilização política e também na dimensão educativa dos acampados, haja vista as tarefas e a discussão coletiva provenientes desse espaço de auto-organização. A sua existência é um fator motivador de um conjunto de pessoas à adesão ao movimento social, um meio de 
socialização de vivências, organizado através de uma pequena vila ou até, de acordo com a extensão de cada um, de uma cidade de barracos de lonas pretas, no qual é instituído, através de uma estrutura organizacional específica, um conjunto de regras, as quais devem ser seguidas. Segundo Shimidt (1992, p. 638).

O acampamento não pode ser visto, no entanto, apenas como uma forma de luta: o novo espaço que se organiza é também um espaço de sociabilidades, no qual se estabelece uma complexa rede de interações que serve como suporte para a construção de novas definições acerca da realidade social ... para as famílias dos agricultores, a estruturação desse território inaugura o "tempo de luta". Ao ingressar em suas fronteiras, os "colonos" identificam-se publicamente enquanto uma coletividade, que compartilha aspirações e direitos comuns.

O acampamento, pensado como parte do processo organizativo do MST, é um espaço privilegiado da educação informal produzida no movimento e também desenvolve um importante papel na inserção de novos integrantes ou de novas famílias na luta social pela Reforma Agrária. Além do mais, adquire um papel central na sustentação do movimento social, no momento em que, através dele e das atividades desempenhadas pelas instâncias de sua organização interna, se torna possível à renovação da base social do MST e da sua direção política.

A vivência no acampamento representa um período transitório na vida de cada trabalhador/a, determinado pela espera da desapropriação de novas terras pelo INCRA, instituto governamental responsável pela política de reforma agrária.

O papel atribuído a cada "Sem terra" no interior do movimento pode estar relacionado com o tempo que este permanecerá no acampamento, tendo em vista que aqueles que ocupam cargos de direção política no/do acampamento, muitas vezes, passam a sua vez na lista de espera do lote, para continuarem na organização de novos acampamentos. Cabe ressaltar que alguns casos de ocupações de terras, principalmente os das famílias precursoras nas "ocupações de terra", chegaram a permanecer até dez anos sobre a terra sem a desapropriação, e outros casos, seis ou quatro anos, tempo que configura um longo período de espera para a regularização da propriedade da terra.

A caracterização de um acampamento passa pela análise de uma série de elementos culturais, organizativos e educativos, que potencializam a transferência e a criação de valores e contribuem para a inserção de novos integrantes ao MST, ou simplesmente para 
a luta pela terra. Com isso, um conjunto de símbolos foram construídos no decorrer dos anos - a bandeira, o hino, o conhecimento da história da luta pela terra no Brasil, a ênfase em valores como a solidariedade e a justiça social - cujos valores são transferidos através da "mística",ii, que se apresenta em espaços formais, como teatro, arte, poesia e músicas, ou espaços não formais, como marchas e mobilizações. A mística tem uma dimensão educativa que impulsiona processos de conscientização política e o engajamento.

A construção de um ambiente que possibilita o fomento a determinados valores sociais é fundamental para a construção do discurso da chegada a terra como a conquista de um direito que provém do resultado da sua luta social e organização política e não como um direito concedido pelos governos ou pelas elites. Entre os muitos aspectos da relação de poder contida neste discurso está o da dignidade humana e social, resgatada, construída e recorrentemente lembrada a cada lutador social, como meio de empoderamento social. Segundo Gohn (1997, p. 53), "quanto mais a massa se apega aos símbolos, aos líderes, e à organização, mais ela luta, mais se mobiliza e mais se organiza".

Outra característica importante da organização interna do acampamento está relacionada à forma de construção do poder de decisão sobre as ações do movimento. Segundo os dirigentes, o poder de decisão sobre as ações empreendidas pelos integrantes do movimento deve vir das instâncias da sua organização, e não de fora da organização, como partidos políticos ou entidades aliadas, e esse seria um aspecto para denotar o sentido autônomo do movimento social frente a outras organizações políticas e instituições do Estado.

A partir de Oliveira (2012), em pesquisa realizada no âmbito de acampamento de sem terras, pode-se identificar o seguinte organograma político-organizativo: 


\section{Figura1 . Organograma político do acampamento do MST ${ }^{\text {iii }}$.}
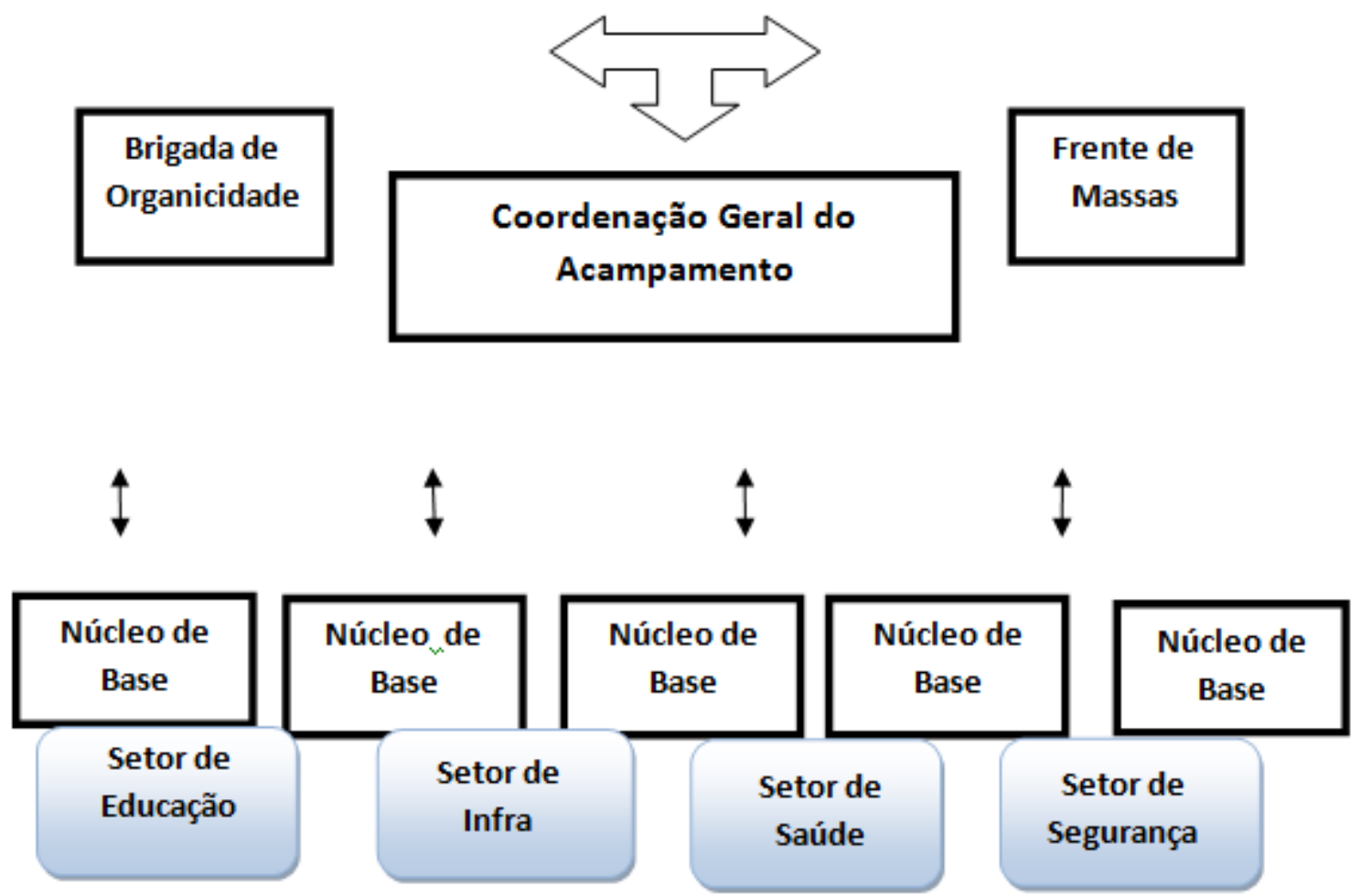

Fonte: Adaptação de organograma de Oliveira (2012), pelas autoras.

Essa estrutura político-organizativa pode ser encontrada nos acampamentos construídos atualmente pelo MST e pode ser considerada parte do acúmulo das experiências em organização resultante de, pelo menos, três décadas de organização de acampamentos de "Sem terra".

O núcleo de base está na fundação desta estrutura. E é o espaço em que todos os integrantes do acampamento estão incluídos, participando do debate dos assuntos da vida interna do acampamento e também dos debates e decisões sobre as ações que serão empreendidas. Cada núcleo se constitui de vinte e cinco famílias, aproximadamente. A partir de cada um deles, são eleitos um ou dois integrantes que irão compor a coordenação-geral do acampamento.

$$
\text { A coordenação-geral do }
$$
acampamento se reúne sempre que demandada para planejamento de ações, de mobilização dos acampados, de decisões sobre as ações de confronto. Além disso, tem por objetivo, em alguns casos, trazer a posição dos acampados sobre temas colocados para a discussão; não se reúne, no entanto, com a mesma intensidade e a 
mesma frequência que a Brigada de Organicidade. Esta se caracteriza por ser composta por um conjunto de acampados/as, reconhecidos/as como "militantes", o que significa uma forma de distinção social em relação aos demais, uma vez que possui suas particularidades, principalmente no que tange a aspectos políticos. A sua forma de eleição é diferenciada da coordenação-geral, pois os seus integrantes são convocados por aqueles/as que já fazem parte da Brigada de Organicidade, sendo referendados em reuniões das demais instâncias organizativas.

As setoriais são semelhantes aos grupos de trabalho, pois são responsáveis pelas atividades da vida prática do acampamento. O setor de educação é responsável pelo ensino das crianças do acampamento, e, em algumas vezes, pela alfabetização de jovens e adultos; o setor de saúde organiza a farmácia do acampamento, (fundamental no trabalho de assistência aos/às acampados/as); o setor de segurança, por sua vez, é muito valorizado devido às situações adversas de confronto em que os/as assentados/as estão colocados; ao setor de infraestrutura se colocam as tarefas relativas à construção dos barracos de lona preta e às estruturas básicasa serem construídas.
A Frente de Massas tem uma importante função devido ao papel desenvolvido por ela na aproximação e no recrutamento de novos integrantes para o movimento e, por consequência, na renovação de sua base social. Os/As acampados/as que estão na Frente de Massas desenvolvem sua tarefa fora dos limites do acampamento e empreendem um processo de convencimento de famílias que se encontram em uma situação de vida precária para vir ao acampamento “engrossar as fileiras" do MST e ingressar na luta pela terra.

João, por exemplo, desenvolve esse significado e importância em seu relato:

Eu trabalhava na frente de massa, convidando para acampar, e eu abrangia de El Dourado do Sul até Camaquã, viajava toda essa região aí, na época, né, aí surgiu esse lote aqui, eu tinha direito. Eu digo aguenta isso aí e fica, fiquei quatro anos (no acampamento) e não me arrependo, feliz da vida que, se tivesse ficado quatro anos trabalhando não tinha conseguido 24 hectares de terra que nem eu tenho. Então eu não posso me queixar. Muita gente e graças a Deus com meu trabalho eu consegui acampar, assentar muita gente, no meu período foram assentadas mais de 1.300 famílias. Eu vou te dizer que ajudei a assentar essas famílias nas fazendas improdutivas. Então isso para gente é um orgulho, né, hoje eu encontro os meus companheiros fora da região aí, o pessoal em Pelotas, então é muito gratificante o pessoal vim e te agradecer, hoje, estão assentados, não graças a eu, porque eu não dou terra 
para ninguém, né, mas eu ajudei eles a chegar em cima do lote, né, que é o sonho de cada um, tem uns que dizem que ganharam o lote, o lote não se ganha o lote se conquista com o maior sacrifício (João, 50 anos).

\section{A experiência do "tempo do acampamento"}

A adesão ao MST traz, num primeiro instante, a vivência do acampamento, e este período é caracterizado pelos/as trabalhadores/as como uma experiência particular, denominado por Shimidt (1992) como "o tempo do acampamento", o qual também pode ser definido como uma etapa de mobilização permanente do processo que envolve a conquista do lote, [e] constitui-se basicamente no tempo de vivências coletivas que caracteriza o processo de formação da identidade "Sem Terra".

A relação entre as trajetórias sociais não é mecânica, na medida em que diversas variáveis interferem na forma como diferentes vivências são significativas. As experiências históricas não são sempre atualizadas da mesma forma, passando pela mediação do contexto que está sendo vivido (Shimidt, 1992, p. 163).

Trazidas sob a forma de memórias, as referências dos camponeses do assentamento Padre Réus são ligeiramente identificadas como difíceis, ou seja, como um período de enfrentamento de dificuldades, no qual "se aprende a dar valor às coisas" - essas coisas entendidas como elementares à sobrevivência, como um lugar para dormir ou ter do que comer. Caracterizam-se por um período em que, segundo a Júlia (28 anos), não se comia carne e que os grãos de feijão eram contados para cada família.

Os/As assentados/as passaram pelo menos por dois momentos de acampamento: o primeiro foi o ponto de encontro e formação do assentamento no município de Piratini, que, de acordo com o Paulo (65 anos), lá eles contribuíram na ação de ocupação da Fazenda Rubira, a qual, anos depois, foi transformada em um assentamento rural; o segundo momento, refere-se a quando partiram em marcha até Viamão, onde se estabeleceram e permaneceram até a conquista da terra.

Lá é uma escola, por causa do pessoal, ia muito pessoal de vocês lá, da faculdade, muitas pessoas de outros países também, para aprender, ver como é que é a situação, não é muito fácil, só que tem que dizer que vou acampar e ficar, naquela época tinha que resolver o problema com a polícia, porque sempre foi assim, só que agora está melhor, porque antes a polícia chegava lá e batia, sabe, hoje tem negociação, tem o Marcon, esse deputado, sabe, eles chegam na frente, sabe, várias vezes a polícia chegou e nós ia apanhá, eles chegam na frente, negociamos na hora $\mathrm{e}$ mandam a polícia parar. Levemos dezesseis tiros uma vez lá em Piratini. Teve ocupação da fazenda Rubira, que hoje é assentamento. No 
mais é bom, é bem divertido, no modo assim, tudo se dá bem, tem escola, tem comida, só não tem carne. Tem um servicinho, tem que trabalha, eu não posso me queixar (Paulo, 65 anos).

O acampamento foi o ponto de encontro de diferentes pessoas, com origens e faixas etárias diversificadas. Mário, o coordenador do assentamento e da regional do MST, lembra que do município de Sapiranga partiram seis ônibus para o acampamento em Piratini. Naquele tempo, fazia parte do Sindicato dos Sapateiros, em cuja sede local teve o primeiro contato com os membros do MST. Eles estavam em fase de recrutamento para a formação de um novo acampamento e procuravam um canal de diálogo com os moradores da periferia da cidade para propor a adesão ao movimento. $\mathrm{O}$ entrevistado fala ainda que já exercia atividades políticas quando estava trabalhando na indústria calçadista, em Sapiranga, e que foi demitido após organizar uma ocupação para moradia numa área verde pertencente à prefeitura municipal. Diz que, na época, foi estimulado a tomar a decisão de acampar pela telenovela "Rei do Gado" (1997), de Benetido Ruy Barbosa, que passava na Rede Globo.

Em geral, as famílias que inicialmente foram assentadas no Padre
Réus, conheceram-se no período do acampamento. Mário conta que o acampamento era organizado através de núcleos que eram formados a partir da organização de vinte e cinco famílias. O núcleo de que ele participava foi sorteado pelo MST para o assentamento em Encruzilhada do Sul.

Segundo Mário, no início, todos os/as assentados/as sentem-se "estranhos", mas isso só até começarem as reuniões. As reuniões passam a fazer parte do cotidiano dos/as assentados/as e tomam um lugar fundamental no processo organizativo do acampamento, já que assim, por meio das afinidades que surgem, vão se constituindo os núcleos.

A relação era toda boa porque a gente chega lá, em dois três dias a gente é tudo estranho um do outro, depois a gente começa a fazer reunião e daí no acampamento a gente começa a trabalhar, o trabalho de base que é chamado pra unir as pessoas e tira um relacionamento e a partir dali as pessoas começam a se conhecer e formam os núcleos, são até vinte e cinco famílias por núcleos, e ali é um pega o setor da educação, outro o setor da saúde, da segurança (Mário, 45 anos).

Alguns elementos são relevantes na construção política e social da identidade "sem terra": a vivência no acampamento, a influência do conjunto de símbolos e a situação de exclusão social. Esse último é 
caracterizado por aqueles de origem urbana como desemprego, a falta de moradia; ou, por aqueles vêm do campo, como a perda de suas terras ou falta de acesso às mesmas. .

Esse espaço de reuniões do acampamento, a pré-disposição às ações propostas pelo MST, como uma marcha ou uma ocupação de terras, as viagens para outras cidades, a participação em atos públicos e manifestações, bem como o compartilhamento dos poucos recursos elementares vão fazendo parte dos ensinamentos da vivência coletiva. Conforme o relato de Júlia,

No acampamento tu não tem estrutura nenhuma, tu não tem água, não tem luz, não tinha cama, não tinha nada. Para fazer uma cama era uns colchão, cravava uns pau e botava a dormir, de manhã cedo caia uns pingo d'água gelado ainda, né, porque ela (a barraca) soa bastante. Comida também era dividida em grãozinho pra cada um, leite também muito pouco, não tinha quase nada pras criança pequenas que nós tinha, mesmo. Lavava roupa na sanga, essas coisa (Júlia, 28 anos).

\section{A experiência de trabalho no assentamento}

Tem-se a impressão de que a condição de assentado, que coloca o indivíduo na condição de pequeno proprietário rural, não dissolve completamente a identidade "Sem terra", haja vista que a própria relação com o movimento é mantida de diferentes maneiras, seja através da forma política mais tradicional, que elege uma representação do assentamento para a composição da instância de coordenação estadual do MST, seja através de relações de solidariedade com aqueles/as que estão acampados. Essa foi uma das situações relatadas por Vera, ressaltando que os assentados/as do Padre Réus contribuíram com alimentos de sua produção para o acampamento do MST em Canguçu, cidade vizinha.

A sede do acampamento, antiga casa da Fazenda Santa Rita, é um ponto de encontro entre os jovens para jogos de futebol nos finais de semana e, eventualmente, nos dias de semana.Também é o local onde são realizadas as missas e os cultos. Alcina (59 anos), por exemplo, é crente, evangélica da Igreja Pentecostal, mas era assistente do padre no acampamento. Ela lembra que, no acampamento, as missas eram ecumênicas; "não tinha essa divisão por religiões", porque assim era deliberado pela coordenação do acampamento. Atualmente, cada um pode marcar um dia diferente para realizações de suas respectivas cerimônias religiosas na sede.

Percebe-se a construção de uma rede social interna ao MST. O espaço de 
circulação social dos/das assentados/as está muito marcado pelas relações internas ao movimento. Este exerce sobre suas vidas uma influência maior do que, por exemplo, exerceria se estivessem vinculados a um sindicato. O seguinte fragmento ajuda a problematizar essa relação. Para Santos e Costa (1997, p. 109),

quando o sindicato conseguia resolver o problema de um assalariado, você podia contar com a perda daquele associado. Quando o trabalhador recebia um benefício, férias de dois anos, salário mínimo atrasado de dois anos, o esforço do sindicato traduzia um efeito contrário ao esperado no que se refere à capacidade de atração: ele pegava o dinheiro e ia embora, e nós perdíamos o associado.

Sugere-se aí que o fenômeno que envolve a vida do/da trabalhador/a que adere ao MST e passa pelo processo de conquista da terra, tornando-se assentado rural, é mais sólido do que a forma de participação que se verifica em sindicatos em regiões urbanas e rurais. Talvez isso ocorra porque se aproxima, nas experiências organizativas do período de acampamento, de outros movimentos sociais urbanos, que, de certa forma, temse como referência, como o Movimento Nacional de Catadores e Recicladores (MNCR), ou o Movimento Nacional de Luta pela Moradia (MNLM), ou ainda os acampamentos do Movimento de
Trabalhadores Desempregados (MTD). As famílias, no entanto, depois de assentadas, continuam sendo motivadas para o exercício de uma participação política. Tal participação pode ser tanto nas questões específicas de mobilização de recursos quanto em lutas mais gerais, como, por exemplo, contra o deserto verde, assim chamada a silvicultura, discutindo os modelos agrícolas ou o fim da violência no campo. Essa dimensão de participação constitui-se um diferencial em relação aos demais movimentos sociais.

A construção da identidade políticosocial do "Sem terra" é uma estratégia desenvolvida pelo movimento para o fortalecimento dos laços de grupo, evidenciando-se como um fator de identificação entre os diversos coletivos que compõem o conjunto do MST. Ademais, é na relação de convivência entre os pares que, com diferentes trajetórias e em diferentes etapas da vida, estão colocados numa mesma condição de sobrevivência, alimentando uma perspectiva de futuro e estratégias de sobrevivência semelhantes, objetivada na conquista da terra. Essa é uma análise possível principalmente quando se olha a organização dos trabalhadores "Sem terra" de dentro para fora, verificando-se seu processo de mobilização, organização, seus instrumentos de luta social e produtos da 
atividade política e, a partir dessas questões, a forma a qual significa sua ação. No entanto, existem outras forças sociais atuando em oposição a essa organização que também interferem nesse processo de constituição da identidade, pois têm capacidade igual ou maior de produzir opiniões e disputar a consciência da sociedade. Se por um lado se cria uma determinada coesão interna à organização, promovendo as condições necessárias para empreender a luta política e social, por outro lado, forças antagônicas estão preocupadas em afastar setores da sociedade da luta dos "Sem terra", colocando barreiras e obstáculos à efetivação da política de reforma agrária. Como exemplo de uma expressão radical desse pensamento, está o Manifesto de Repúdio aos Sem Terra, distribuído apocrifamente, em 2003, nas proximidades da cidade de São Gabriel, no Rio Grande do Sul, quando o MST realizava a marcha Sepé Tiaraju, mas atribuído aos latifundiários da região. Citado por Brum (2006, p. 20),

\section{GABRIELENSES DIZEM NÃO À INVASÃO E A SEUS APOIADORES ${ }^{\mathrm{iii}}$}

Povo de São Gabriel, não permita que sua cidade tão bem conservada nesses anos, seja agora maculada pelos pés deformados e sujos da escória humana. São Gabriel, que nunca conviveu com a miséria, terá agora que abrigar o que de pior existe no seio da sociedade. Nós não merecemos que essa massa podre, manipulada por meia dúzia de covardes que se escondem atrás de estrelinhas no peito, venha trazer o roubo, a violência, o estupro, a morte. Estes ratos precisam ser exterminados. Vai doer, mas para grandes doenças, fortes são os remédios. ... precisa correr sangue para mostrarmos nossa bravura. Se queres a paz, prepara a guerra, só assim daremos exemplo ao mundo que em São Gabriel não há. lugar para desocupados. Aqui é lugar de povo ordeiro, trabalhador $\mathrm{e}$ produtivo. Nossa cidade é de oportunidades para quem quer produzir e não há oportunidades para bêbados, ralé, vagabundos e mendigos de aluguel. Se tu, gabrielense amigo, possuis um avião agrícola, pulveriza a noite 100 litros de gasolina em voo rasante sobre o acampamento de lona dos ratos. Sempre haverá uma vela acesa para terminar o serviço e liquidar com todos eles.

Se tu, gabrielense amigo, és proprietário de terras ao lado do acampamento, usa qualquer remédio de banhar gado na água que eles usam para beber, rato envenenado bebe mais água ainda. FIM AOS RATOS. VIVA O POVO GABRIELENSE.

Outra alusão às oposições se dá através da grande mídia quando faz "vistas grossas" aos assassinatos de lideranças rurais e camponesas nos conflitos de terra no Brasil, ou de partidos políticos que atuam nacionalmente contra a reforma agrária. A tentativa de instalação da Comissão Parlamentar de Inquérito do MST, em 2009, é outro exemplo. A 
identidade, sendo construída na dualidade desse confronto de forças, disputa política e guerra de posições.

\section{Sempre "Sem terra" ou camponeses?}

A discussão sobre a produção dos assentados pode ser considera a questão central da transformação do referencial dos "Sem Terra", construída nos marcos da experiência no acampamento para uma nova realidade que se traduz na condição de camponês.

As famílias do Assentamento Padre Réus viveram um período difícil de adaptação a essa nova condição, visto que, quando chegaram na terra que estava ainda em processo de demarcação, ficaram pelo menos um ano inteiro acampados, contando com poucos recursos para sobreviver. Rememorou-se que, quando chegaram a Encruzilhada do Sul, talvez estivessem em situação pior do que a que se encontravam no acampamento. Alguns pensaram em desistir, mas permaneceram ali até chegarem os primeiros recursos materiais e financeiros para construir moradias e investir na produção.

Em 2011, a realidade mudou, pois já se podia contar com outra infraestrutura. Todo/as possuíam casa, algumas com galpão e muitas com galinheiro, chiqueiro, acesso a eletrodomésticos, televisão, rádio e, os mais estabelecidos, atém mesmo, possuíam carros.

A prioridade para todas as famílias foi pensar na produção de alimentos. A dificuldade com a própria alimentação, no primeiro ano de estadia, traduziu-se na preocupação pela agricultura de subsistência. Podemos constatar isso através da observação e do destaque em todas as entrevistas quanto à essa questão, apontada como prioridade. Nesse sentido, a realidade atual dos assentados colabora para a ideia de Ploeg (2008, p. 49), quando afirma que o modo de vida do camponês contribui para a produção de riqueza social na medida em que existe, no interior da unidade produtiva, uma lógica de desenvolvimento endógeno cumulativo, diferente da lógica de rupturas da agricultura empresarial.

Está em andamento, portanto, um processo de organização dos/das trabalhadores/as para a produção que ocorre por intermédio do trabalho associado no Assentamento Padre Réus. A associação é composta pelas famílias e tem por interesse discutir a produção e o comércio. Essa organização é muito incipiente e, conforme se observa, as estratégias estão sendo discutidas no âmbito familiar.

A produção para o consumo diversos é diversificada e os principais cultivos para 
o comércio são o milho, o feijão, o arroz, o fumo.

Algumas famílias receberam o lote com plantação de eucalipto e utilizam o comércio da madeira como um acréscimo de renda. Outros decidiram plantar o eucalipto com a justificativa de incrementar a própria renda. Existem aproximadamente cinco famílias envolvidas com o plantio do eucalipto, no assentamento. $\mathrm{O}$ município de Encruzilhada do Sul excedeu o limite de terras plantadas pela silvicultura, já que empresas compraram terras e não conseguiram o licenciamento ambiental para o plantio.

Além desses produtos, nove famílias estão envolvidas na fruticultura, produzindo uva, pêssego e amora, as quais fazem parte de um projeto que envolve duzentas e setenta famílias no município. Nesse projeto, cada família recebeu setecentas mudas de frutas, além de calcário. Elas encontraram saída para a uva e a amora, mas não encontraram uma maneira de escoar a produção de pêssego, pois não recebem auxílio do poder público municipal.

Estamos se organizando em reunião, tem a associação, de trinta e sete famílias, temos trinta associados, só sete que não quis vim. Estamos discutindo a produção, a plantação, e o comércio, e agora estamos discutindo o comércio, como eu sou dirigente estadual aí eu tenho que discutir todos os assentamentos e já estamos trazendo agroindústria de frutas, pêssego, uva, amorinha. De pêssego já tem uns cinco hectares, de maça já tem duas hectares, parreira já tão começando e amorinha também, a sede vai se lá no Segredo Farroupilha (Mário, 45 anos).

O próximo passo, de acordo com os/as agricultores/as, é a construção de uma agroindústria para agregar valor à produção e encontrar uma melhor comercialização dos produtos. A sede será instalada no assentamento Segredo Farroupilha, e a construção prevê o custeio de projeto encaminhado por deputado federal apoiador do MST.

Sobre os mecanismos de produção coletiva, sistemas de cooperação elaborados pela associação, não se encontrou nenhuma reposta concreta, senão o desafio de construí-los, como foi colocado nos discursos das lideranças.

A agricultura praticada pelos/as assentados/as foi basicamente subsidiada pelo governo federal, em forma de créditos específicos que devem ser ressarcidos ao final de cada ano. Esse crédito foi importante para o estabelecimento dos agricultores na terra, já que este primeiro momento de adaptação e reconhecimento do território, qualidade da terra $\mathrm{e}$ possibilidades de produção conjugado com 
a pouca experiência de muitas famílias, torna a vida complicada.

Mesmo com subsídio, a inserção agrícola dos/as trabalhadores/as está em uma lógica desigual de comércio em relação aos grandes empresários agrícolas. Isso se expressa na seguinte fala: "tem que vendê dez sacos de milho para paga dois de adubo”. O limite não está no potencial de produção de alimentos em si, mas no custo-benefício das famílias na inserção em um mercado sustentado por uma lógica de produção que não é sustentável e a mais adequada ao modo camponês de bemviver.

A imposição do receituário da agricultura empresarial, que tem o interesse de impor ao/à agricultor/a o consumo do adubo, da ureia, dos herbicidas, das sementes geneticamente modificadas, da mecanização e de uma técnica fabricada nos centros especializados, é possível com a perda do conhecimento tradicional de técnicas autossustentáveis de produção em relação aos recursos naturais, de modo que a forma de proceder o manejo da terra passa a ser embasado numa forma empresarial de fazer agricultura. Essa imposição de regras coloca o impasse entre a adesão do assentado ao modelo agrícola e à exclusão do mercado.

\section{Considerações finais}

É interessante observar que existem dois momentos nesta trajetória descrita acima. O primeiro momento consiste em trabalhadores/as desempregados/as, demitidos da indústria calçadista da região onde moravam, em busca de alternativas de sobrevivência. A alternativa que surge é o movimento social. Esta trajetória está marcada pela problemática do trabalho. $\mathrm{O}$ segundo momento, o "tempo de acampamento", entendido como espaço de auto-organização, e que consiste na efetivação uma experiência formativa para esses/as trabalhadores/as, na luta e à espera da terra, sua força produtiva.

Essa experiência formativa tem, na questão organizativa e na mística do movimento, um momento de aproximação com a realidade rural, através da valorização do trabalho camponês, do cultivo à terra, da produção de alimentos, quando de fato é promovida a valorização do. Para Ribeiro (2009, p. 50),

Trata-se de uma situação desafiadora, porque a ação formadora que integra esses três componentes - arte, cultura, intenção - deve ter como objetivo a modificação de um sistema de referências ou um modo de funcionamento de uma dada situação ou realidade. É desafiadora porque as situações de mudanças não são triviais e, embora em algumas situações as mudanças possam até 
acontecer com relativa rapidez, nem sempre é assim.

Nesse sentido, o assentamento das famílias passa por um processo de mudança de referenciais, obtida nesse processo formativo, construída no movimento social. Isso se pode auferir nas falas em que aparece o trabalho como princípio educativo, no qual ocorre um processo de aprendizado constante, envolvendo a gestão do lote, a escolha das culturas a serem produzidas, a aplicação dos recursos. Isso faz com que o trabalho camponês tome conta do cotidiano das famílias, e, ao mesmo tempo, estimula o aparecimento de laços com o movimento social, como uma forma de aprendizado político para a mediação e gestão dos assuntos coletivos.

Por conseguinte, percebe-se a questão do trabalho como o grande mobilizador dos/as trabalhadores/as em suas trajetórias, aparecendo aí sua centralidade, ou seja, a passagem do trabalho urbano para o trabalho rural como a consequência dessa mobilização. $\mathrm{Na}$ realidade, o que se percebe é o trabalho como princípio educativo presente nas ações do movimento de organização, tanto no nível material, como no nível espiritual, como, por exemplo, na simbologia da mística (sementes, adereços campesinos).
As práticas gestadas e apreendidas no interior do movimento social resultam do trabalho com três diferentes aspectos: organização política, busca de alternativas de trabalho e trabalho como princípio educativo. Esses três aspectos articulados podem expressar a experiência das histórias e trajetórias de vida dos/das assentados/as do Assentamento Padre Réus.

\section{Referências}

Brum, C. K. (2006). Esta terra tem dono. Disputas de representação sobre o passado missioneiro no Rio Grande do Sul. A figura de Sepé Tiaraju. Cadernos IHU Ideias 46.

Gohn, M. G. (1997). Teoria dos Novos Movimentos Sociais: paradigmas clássicos e contemporâneos. São Paulo. Edições Loyola.

Gohn. M. G. (2006). Educação não-formal na Pedagogia Social. 1 Congr. Intern. Pedagogia Social. Março.

EMATER. (2003). Plano de Desenvolvimento Econômico do Assentamento Padre Réus. Encruzilhada do Sul.

Oliveira, V. L. (2012). Militância e Religião no passado e presente da luta pela terra. Sociologias Plurais, 1, 125-148.

Ploeg, J. D. (2008). Camponeses $e$ impérios alimentares: lutas por autonomia e sustentabilidade na era da globalização. Porto Alegre, RS: Editora da UFRGS. 
Ribeiro, R. (2009). O trabalho como princípio educativo: algumas reflexões. Saúde e Sociedade, 18, 42-54.

Santos. R., \& Costa. L. F. C. (1997). Camponeses e política no pré-64. Estudos Sociedade e Agricultura, 8, 83-117.

Shimidt, C. (1992). O tempo do acampamento: identidade político-social do sem-terra. Porto Alegre: UFRGS.

i Segundo Gohn (2006) educação não-formal consiste na educação produzida nas associações coletivas protagonizadas pelas redes associativas da sociedade civil. Educação formal consiste na educação promovida através da ação estatal, como, por exemplo, a escolar, e na educação informal, os agentes educadores são os pais, os vizinhos, os colegas da escola, a igreja paroquial e os meios de comunicação de massa.

ii As místicas utilizam músicas, bandeiras e elementos relativos à vida no campo, como peneiras, chapéus de palha, sementes, pão e alimentos orgânicos cultivados na roça. Esses elementos estariam representando uma agricultura baseada nos ideais de sustentabilidade, livre de agrotóxicos. As Músicas "MST, só a luta faz valer" (1999), de José Pinto Lima, "Procissão de retirantes" (1999), letra de Marjin Cesar Ramires Gonçalves e música de Pedro Munhóz, ambas lançadas no $1^{\circ}$ Festival de músicas da Reforma Agrária, em Palmeiras das Missões, em 1999, e também a "Canção da Terra", de Pedro Munhóz, relançada em 2011 pela banda Teatro Mágico, são trilhas consagradas na realização de místicas. Elas trazem temas como a luta pela terra, a exaltação da terra, a desigualdade social e a partilha do pão.

iii Manifesto de Repúdio aos Sem Terra. Agosto de 2003. Texto recebido por e-mail e atribuído aos latifundiários de São Gabriel.
Como citar este artigo / How to cite this article / Como citar este artículo:

APA:

Lopes, B. S., \& Moretti, C. Z. (2017). O trabalho como princípio educativo no MST: um estudo de caso do Assentamento Padre Réus. Rev. Bras. Educ. Camp., 2(2), 708-727. DOI: http://dx.doi.org/10.20873/uft.2525$\underline{4863.2017 v 2 \mathrm{n} 2 \mathrm{p} 708}$

ABNT:

LOPES, B. S.; MORETTI, C. Z. O trabalho como princípio educativo no MST: um estudo de caso do Assentamento Padre Réus. Rev. Bras. Educ. Camp., Tocantinópolis, v. 2, n. 2, p. 708-727, 2017. DOI: http://dx.doi.org/10.20873/uft.25254863.2017v2n2p708

\section{ORCID}

Beliza Stasinski Lopes

http://orcid.org/0000-0002-7067-3142

Cheron Zanini Moretti

http://orcid.org/0000-0002-6297-3129

Recebido em: 28/06/2017

Aprovado em: 10/08/2017

Publicado em: 10/11/2017 